\title{
ISSUES IN TEACHING TECHNICAL WRITING IN A CROSS-CULTURAL ENVIRONMENT: THE CASE OF NATIVE STUDENTS
}

\author{
Juanita Giesbrecht
}

There is a myriad of issues to consider in designing a technical writing curriculum under the best circumstances; but, when a crosscultural perspective must be employed the task increases in complexity. Technical writing in Canadian community colleges is directed towards giving individuals the skills to function in a predominantly white, middle-class, technological society. If a study were to be conducted, it would probably be found that the very large majority of technical writing teachers are typically white, middle-class, reasonably welleducated, goal-oriented individuals. These same teachers would probably be passing on these cultural values in their teaching--not an unreasonable assumption.

Indeed, education in today's society seems to require a certain way of thinking. Education is very much goal-oriented and deterministic, and success in the educational sense appears to depend upon the extent to which an individual is a linear thinker. Given these criteria it is possible to envision that certain cultures may be dysfunctional for education. In other words, learning problems could arise with students whose home environment is very different from that of the surrounding culture.

In designing a curriculum for the teaching of technical writing, it seems apparent that the cultural differences specifically between Natives and non-Natives must somehow be compensated for. A brief review of the Cree language points to their perceptual separateness. Natives have a tendency to view the world holistically. According to Pelletier [1974], Natives "start with the whole and examine every part in relation to that whole." [p.104] Hawthorn [1967] reports that the Native selfimage is ambiguous; that there is a marked tendency to preserve the traditions, while living in the reality which is the modern world. He notes that if an Indian knows the value system of whites, can speak well, and understands the work ethic, then he will have a better chance of finding a good job and keeping it. [p.168]

The purpose of this paper is to examine some of those issues which ought to be considered in teaching technical writing in a cross-cultural environment. Cross-cultural teaching is an enormously complex subject not within the scope of this paper to develop; however, there are certain cultural factors which can be related to the teaching of technical writing. For the purposes of discussion, culture is referred to as the sum of the way in which a person lives. The cross-cultural 
component refers to Native, specifically Cree, and non-Native interaction. Although opportunity to take an anecdotal approach to the subject exists, the issues will be presented through a review of some of the literature focused particularly on cultural differences between Natives and non-Natives.

The review of the literature could serve as a theoretical base for designing a curriculum that considers the cross-cultural dimension in technical writing. An examination of the issues is justified in light of the increasing numbers of Native students seeking post-secondary education in community colleges, particularly northern community colleges.

Assumptions made in the paper include: 1) Native students typically have a language other than English as their first language; and 2) Native students seek the type of education which will qualify them for success in the non-Native society.

\section{LITERATURE REVIEW}

\section{Characteristics of Technical Writing}

There appears to be general agreement in technical writing texts that certain characteristics are essential to good technical writing. [Blicq,1982; Dagher,1978; Houp and Pearsall,1980] Some characteristics upon which these authors agree include: 1) knowing the reader, or reader orientation; 2) correct use of language, specifically correct spelling, grammar and punctuation; 3) good organization; and 4) proper presentation.

Given that readers bring their own perceptions and experiences to the reading process, it would seem logical that careful audience analysis should characterize the technical writer's approach. Audience analysis includes knowing the background of the audience--who the readers are, what they know and what they do not know. It is important for the writer to know when terms require explanation and when elaboration on a point is necessary. [Houp and Pearsall, 1980,p.67] According to Dagher [1978], the writer has to know certain characteristics of the reader including age, occupation, education, and organizational membership. "When the writer or speaker knows the receiver's occupational and educational experience in a certain technical field, he or she can decide what kind of technical terms to use, how much explanation is needed, and how deeply to analyze a complex subject." [Dagher,1978,p.91] In other words, the writer must have a good understanding of the intended reader in order to be able to write effectively.

The reader is so important in technical writing that any technical document, whether it is a letter or a report, begins by telling the reader immediately what he/she needs to know. Blicq [1982] employs a 
method called the pyramid technique "so named because it starts at the top with a small morsel of essential information and then substantiates it with a broad base of details, facts and evidence." [p.300] The basic assumption seems to be that a reader of technical information is a busy individual who cannot afford to wade through masses of words, facts, and figures, wasting valuable time, to find the most significant and salient points of the document. Technical writing has certain attributes supporting this position. Any information conveyed must be pertinent to the issue; thus the information must be specific to the stated purpose of the communication. The vocabulary tends to be specialized on the assumption that the readership will be familiar with the terms. Because the technical document is so packed with information another assumption is that the reader is very highly motivated to read the document. [Houp and Pearsa11,1980] 0lson, Duffy and Mack [1980] suggest that much of an intended message is transmitted by implication, thus confirming that the writer and the reader must at least have a common base of understanding. [p.69-70]

While there appears to be a dearth of literature on the subject as applied to writing, 01son, Duffy and Mack [1980] note that research in both cognitive psychology and artificial intelligence "has conclusively demonstrated that general knowledge plays an important role in understanding even simple sentences and texts." [p.70] Correct use of the language in terms of proper grammar, punctuation and spelling is critical in technical writing. Written communication demands clarity, conciseness and correctness because writing is a one-way process without the advantage of immediate feedback. Since the language of writing tends to be more formal than speech, it is imperative that correct grammar and punctuation be used to perpetuate the formality. While language use is flexible, growing, and changing, it is important to observe certain conventions, since "certain constructions are considered errors, and the person who uses them is considered illiterate or uneducated." [Houp and Pearsa11,1980,p.452] A rationale for proper use of punctuation and grammar is obvious and not within the scope of this paper to elucidate; however, a general comment might be that the student who cannot use the language effectively is certainly at a disadvantage. [Weinberg, 1971]

Good organization or logical development of thought characterizes good technical writing. The writer engages in linear thinking or movement in a fairly direct manner from one position to another; for example, cause and effect. It would appear that technical writing depends upon linear thinking. To prepare a report, for example, one has to select a topic, gather the information, analyze the audience, organize the information, observe the writing conventions, write a draft, rewrite, and submit the report--usually in that order. [B]ica, Houp and Pearsall, et al] In other words, the stages in the development of a technical document are clearly delineated. Further, Dagher [1978] notes the "predetermined purpose" of any technical communication is "the response the person writing or speaking wants from the intended receiver." [p.70] This supports the linear aspect of logical 
consequences. Most technical writing is in the form of exposition, or writing which explains something. In expository writing, organization is critical. The writer must begin with a topic sentence or controlling idea, then develop it. [Drew et al,1982]

Proper presentation is the mechanical device drawing all parts together. As Houp and Pearsall [1980] note, the elements of the report are determined by the complexity of the subject and the needs of the audience. The more complex a report, for instance, the greater the need for a table of contents. Similarly, graphic aids assist a reader to understand a report. [p.183] The presentation of technical writing is important because it conveys an image which can either enhance or detract from a case. [B1icq,1982] Further, according to Blicq [1982], a presentation has the job of suiting the purpose of the report and fitting the subject it describes. Another reason for adhering to the presentation guidelines relates to the readership issue. Readers of technical writing have certain expectations about material they are to read. One expects a table of contents as a locating device; one expects proper documentation to authenticate resources; one expects a logical development of information. These expectations have implications for continuity. Further, "nonfunctional, poorly planned reports do little for their readers or their authors." [Houp and Pearsa11,1980,p.254]

\section{Cross-Cultural Factors}

Given the generally accepted premise that Natives have a different culture, it would appear that "knowing the reader, " particularly if the reader is non-Native, might present problems for Natives doing technical writing. Thus it could be said that certain aspects of the Native culture may militate against Native students learning technical writing with ease. Clifton [1977] contends that:

Specific groups of students may not succeed in the educational systems because their general cultural values are not congruent with the cultural values of the society, or their instrumental values are not congruent with those required in the school. [p.187]

Havighurst [1972] supports this view: "An Indian's ability to function well in school depends upon how well his culture matches that of society which surrounds him." [p.92] Walsh [1972] has observed that there is nothing from the Indian culture represented in school or valued by it. This and two other factors contributing to a low degree of confidence and a poor self-image in Indian students further exacerbate the cultural differences. The other factors are: 1) the Indian child gains toe impression that nothing he or other Indians do is right compared with what non-Indians do; and 2) a general assumption is made that educators want to help Indians to improve, leading to the obvious conclusion that what is being done now is wrong or even inappropriate. 
Clifton [1977] notes that the verbal and numerical dimensions of cognitive ability are affected by cultural, environmental and ethnic factors. He states:

Indian students probabiy have poor academic performance not simply because they are Indians but because they have values, language facilities, cognitive abilities, and patterns of interaction which are not congruent with those expected in the education system. [p.200]

It is reasonable to conclude from this that the self-concept of the Native student may be less positive than the self-concept of the nonNative student.

While it is generally recognized that socialization is a function of education, Hawthorn [1967] states that the home and school are two different cultural entities. The differences are found in such factors as attitudes towards the child, parental interest in learning, verbal practice and development, sanctions for learning, routines for learning, and discipline. [p.110] As Hawthorn notes:

The child who has familiarity with books, who has been engaging in conversations with adults, who has an extensive vocabulary and who knows how to use words is at a distinct advantage compared to the child who has had little verbal interaction, no exposure to books, and who has learned English from adults who use it as a second language. [p.114]

Price [1978] observes that the Native student faces certain problems in school due to the nature of his or her lifestyle. Some of the handicaps which he claims are a function of Indian life include poverty, an emphasis on physical rather than on intellectual pursuits, language and value conflicts. He suggests that the traditions of Native people are in sharp contrast to the non-Native environment:

The students are coming from a tradition of close family solidarity and co-operation, mutual support of kinfolk, co-operation among age cohorts, and belief in the value of the past; they are thrust into an environment whose values emphasize autonomy, competition, materialism, future orientation, hard work, and punctuality. [Price,1978,p.271]

Pelletier [1974] notes "white people live in two kinds of time, the past and the future. Indians, on the other hand, live in an eternal present." [p.104] According to Sealey and McDonald [n.d.], Indian people have a variety of characteristics different from non-Indian people. Indian people, it seems, have a present orientation, a tendency to satisfy present needs as opposed to working to get ahead. There is the sense that time is always with us. Kinsella [1977] offers an interesting perspective: 
Nobody like old Joe much. Reserve Indians don't like that he don't be like them: do nothing; and the white people sure not like it that he think he can be same as them. That's what the white people think...old Joe, last thing he ever wants is to be white. [p.61]

As Sealey and McDonald note, "When people communicate cross culturally.. . there are a number of cultural refractions which distort the message." [p.79] Refraction in this sense refers to something which appears to be what it is not. The major cultural refraction relevant to the topic of technical writing is verbal. One of the things which happens to persons who cannot use, for example, the English language, is alienation from persons who do use English properly. Weinberg [1971] has noted that "language is deeply linked to the values and orientation of different classes." [p.64]

\section{Cree Language}

Because Native students attending community college in Northern Manitoba or Saskatchewan will typically be Cree, this discussion will centre on the Cree language and the verbal communication problems which can occur. Potential areas of difficulty include word sounds, word order, tense, gender, use of pronouns, descriptive adjectives, and possessive case.

Cree is an Algonkian dialect. According to Sealey [1973]:

It is a language of beauty; beauty of sound, clarity, preciseness, regularity. It is a language of richness; rich in words, vowels, imagery and symbols. It is an oral language; a language of oratory and poetry. It contains no harsh sounds. It is a language which, like all languages, has evolved over tens of thousands of years. It allows its speakers to categorize tribal experiences and its structure reflects the interrelationships of language and culture. It serves its people and its structure shapes their world view. [p.81]

Sounds in English and Cree may be the same but they are not used the same way. [Sealey,1973; Wolfart and Carroll,1981] The "sh" sound is non-existent in Cree; therefore, a word such as "machine" may be pronounced "maseen," or "sheep" will be pronounced "seep." Many Cree people will be able to say the "sh" sound but only after prolonged exposure and correction. Sometimes the "sh" is never learned. As well, in Cree the ' $t$ ' and ' $d$ ' do not exist; the sound used is "somewhere in between." [Sealey,1973,p.87] The Cree person will hear a sound not used in Cree but will relate that sound to a familiar sound; thus "bill" becomes "pill" or "boy" becomes "poy." The potential for spelling errors is obvious. Gender is another issue: "The Algonkian languages do not have the concept of gender... . The result of this will be that many speakers, whose first language is not English or French, will have difficulty with the masculine or feminine pronouns." [Sealey and McDonald,n.d.,p.79] 
In English, word order is important to convey the correct meaning. Certainly technical writing demands clarity, conciseness and correctness. $[B 1 \mathrm{icq}, 1982$; Houp and Pearsa11,1980] "In Algonkian languages, word order is of less importance than word form . . . . The order of the words indicates emphasis. . the language is highly verbalized or inflected . . . Inflected languages are ideal for use in abstract thinking." [Sea ley, 1973,p.88]

Previous mention has been made of the use of time. "Cree tense is developed using an entirely different concept from that of English time - . . Cree tense is developed on a continuum whose focal point is present time." [Sealey,1973,p.88] In other words, the verb is timeless. In English there are relatively strict rules governing the use of tense or time in writing. Because the Cree grammatical system lacks the equivalent of the English infinitive, the Cree person will usually avoid using an infinitive. [Sealey,1973]

Sealey and McDonald [n.d.] have observed that:

most Native languages are imagic . . . This imagic predomination, as opposed to abstract terminology, patterns the way people think. In explaining anything, especially when an interpreter must be used, the more imagery that can be used the more likely the listener will grasp the meaning. [p.80]

In other words, when describing something, the Native will try to give a completely holistic picture and draw upon all aspects of a situation in order to describe it.

One final point to be made is that "the Algonkian languages are what we refer to as imperative languages. Polite requests, so common in English, are not easy to express in Cree." [Sealey and McDonald,n.d, p.81] The implications for the technical writer are interesting. It is possible that instead of making a polite request in a memorandum or letter, the request becomes a demand, with its accompanying ramifications. An obvious conclusion is that technical language or very formal English can be confusing to those not completely fluent in English. [Sealey and McDonald,1973]

\section{DISCUSSION}

Cree people have not had a written language until very recently; that is, within the last two hundred years. In 1841, the Rev. James Evans, at Norway House, Manitoba, "invented a syllabic system of writing Cree." [Sealey,1973,p.81] The Native culture has depended upon its oral traditions for generations. The point is that, historically, Native societies have not been writing societies.

Writing demands discipline; writing demands a particular way of thinking. Technical writing demands purpose; technical writing is 
goal-oriented. There is no immediate feedback in writing. Because the Cree language is predominantly a non-written language the propensity to give immediate feedback is strong. It is logical, therefore, to assume that immediate feedback is a critical component of the language. Technical writing is very focused. Pelletier [1974] notes that Natives "start whole and examine every part in relation to that whole." [p.104] This global thinking is not synchronous with linear thinking, a requirement for the technical writer.

It was noted earlier in the paper that the home and school often portray two different cultural entities. This may explain some resistance by Natives to school and what education represents. The education system was developed by non-Natives and until very recentiy taught exclusively by non-Natives. A logical extension of Havighurst's [1972] argument cited previously would be to say that a Native's ability to function well as a technical writer depends to an extent on how much that Native has been steeped in the non-Native milieu.

The non-Native society has been presented as future-oriented, goal-oriented, and to a certain extent competitive and materialistic. The present orientation of the Native society suggests certain socialization patterns which make it very difficult to think about a future. This presents problems for functioning in a future-oriented, technological society. A logical extension of this thought is that writing which is based on knowledge of the non-Native society might prove difficult for a Native to even conceptualize about.

The differences between Native and non-Native language have important implications for the would-be technical writer. The potential for spelling errors was identified earlier. However, another factor is the potential for grammatically incorrect sentence construction based on how words are arranged, given the differences identified earlier between Cree and English word order. The problems could involve, for instance, mixing tenses within a sentence. Because there is no gender in Cree as it is known in English there is potential for using pronouns incorrectly and for Native students to be unable to make correct pronoun-antecedent connections. The tendency for Natives to use imagic language to give the whole or total picture is wasted to a certain extent in technical writing which demands only facts and pertinent detail.

Finally, technical writing is, for all intents and purposes, a solitary activity demanding responsibility, discipline and independence. According to Clifton [1977] "Indian students believe more in external controls than non Indian students." [p.189] This means they may value external controls more. Such controls are contingent upon factors beyond the individual's control; conversely, internal controls are contingent upon one's own behaviour. Technical writing is contingent upon internal controls; that is, responsibility, discipline, independence. Further, the focus of adult education practices is to encourage the student to be in charge of the learning process. The discontinuity of the positions is obvious. 


\section{RECOMMENDATIONS}

Designers of a technical writing curriculum must be prepared to examine the extent to which their curriculum is influenced exclusively by the values of a white, middle-class, goal-oriented, future-oriented, technological society. Many questions present themselves. Further study may reveal the practicality of designing a technical writing curriculum to accommodate the cross-cultural dimension. Before that study occurs though, there seems to be justification for researching whether or not cultural differences do indeed have an impact on a Native student's ability to do technical writing.

Teaching educators about other cultures may be an appropriate beginning. It seems reasonable that a starting point in cross-cultural sensitivity would be to educate the educators. Therefore, part of the continuing education of teachers of technical writing should be courses in cross-cultural education. A model for teaching technical writing in the cross-cultural classroom should be developed and offered to teachers of technical writing as an alternative to traditional teaching methods.

The literature available on the subject of teaching technical writing tends to reflect an ethnocentric viewpoint, specifically the perspective of the white, middle-class, goal-oriented, future-oriented value system. It would be interesting to discover the other perspective and develop from it.

\section{REFERENCES}

1. Blicq, R.S. 1981. Technically-Write! 2nd Edition. Englewood Cliffs, New Jersey: Prentice Hall.

2. Clifton, R.A. 1977. Factors Which Affect the Education of Canadian Indian Students. Education, Change, and Society: A Socjology of Canadian Education. R.A. Carlton, L.A. Colley, N.J. Mackinnon, eds. Toronto: Gage.

3. Dagher, Joseph P. 1978. Technical Communication: A Practical Guide. Englewood Cliffs, New Jersey: Prentice Hall.

4. Drew, Sara N. et al., Delaware Technical and Community College. 1982. Writing Skills for Technical Students. Englewood Cliffs, New Jersey: Prentice HalT.

5. Havighurst, R.J. 1972. Education Among American Indians: Individual and Cultural Aspects. Perspectives on the North American Indian. Mark Nagler, ed. Ottawa: McLelland and Stewart.

6. Hawthorn, H.B., ed. 1966. A Survey of the Contemporary Indians of Canada: A Report on Economic, Political, Educational Needs and Policies. Vol. II. Ottawa: Indian Affairs Branch. 
7. Houp, K.W. and T.E. Pearsal1. 1980. Reporting Technical Information. New York: Macmillan.

8. Kinsella, W.P. 1977. Dance Me Outside. Toronto: Oberon Press.

9. Olson, Gary M., Susan A. Duffy, Robert L. Mack. 1980. Applying Knowledge of Writing Conventions to Prose Comprehension and Composition. New Directions for Teaching and Learning: Learnirg, Cognition and College Teaching. W.J. McKeachie, ed. San Francisco: Jossey Bass, Number 2 .

10. Price, John A. 1978. Native Studies: American and Canadian Indians. Toronto: McGraw-Hill Ryerson.

11. Riessman, Frank. 1962. The Culturally Deprived Child. New York: Harper and Row.

12. Sealey, D.B. 1980. The Education of Native Peoples in Manitoba. Alexander Gregor and Keith Wilson, eds. Winnipeg, Manitoba: University of Manitoba.

13. Sealey, D.B. 1973. Algonkian Linguistics. Indians Without Tipis. D.B. Sealey and V.J. Kirkness, eds. Winnipeg: William Clare (Manitoba) Limited.

14. Sealey, D.B. and Neil McDonald. n.d. The Health Care Professional in a Native Community: A Cross Cultural Study Guide. Winnipeg, Manitoba: University of Manitoba.

15. Snow, Richard E., and Penelope L. Peterson. 1980. Recognizing Differences in Student Aptitudes. New Directions for Teaching and Learning: Learning, Cognition, and College Teaching. W.J. McKeachie, ed., Number 2.

16. Walsh, Gerald. 1971. Indians in Transition: An Inquiry Approach. Toronto: McLel land and Stewart.

17. Weinberg, Carl. 1971. Education and Social Problems. New York: The Free Press.

18. Wolfart, H.C., and J.F. Carrol1. 1981. Meet Cree: A guide to the language. 2nd Edition. Edmonton, Alberta: University of Alberta Press. 
Juanita Giesbrecht has taught at Keewatin Community College in The Pas, Manitoba since 1976. Although her expertise is mainly in the area of interpersonal communications and social sciences, she has spent a number of years developing technical writing courses for a variety of students in the trades and technologies. Her experiences in social work, vocational counselling and living among Native people have given her some insight into the unique problems faced by individuals who live and work and are educated in the cross-cultural environment. 